\title{
Africa and global climate change: critical issues and suggestions for further research and integrated assessment modeling
}

\author{
Paul V. Desanker ${ }^{1, *}$, Christopher O. Justice ${ }^{2}$ \\ ${ }^{1}$ Global Environmental Change Program-Africa, Department of Environmental Science, University of Virginia Clark Hall, \\ Charlottesville, Virginia 22903, USA \\ ${ }^{2}$ Department of Geography, University of Maryland, 2181 LeFrak Hall, College Park, Maryland 20742, USA
}

\begin{abstract}
This special issue is dedicated to research on climate change in Africa. This research has, until recently, taken a back seat to more pressing applied research on natural resource management. As countries of the world position themselves with respect to climate change, it is important for African nations to better understand the likely impacts of climate change on their environment, peoples and economies. African researchers are now starting to address global change research issues, and this special issue provides a sample of recent research on climate change. Climate change must be an integral part of the long-term sustainable development agenda for African nations. Coping with and adapting to climate change requires a strong scientific understanding integrated with socioeconomic and policy considerations. At this time, international efforts are developing the climate change research agendas needed to develop this basic understanding and explore ways to integrate physical and social processes within a modeling framework. The immediate focus is on undertaking regional scale analyses and coupled models suited to the African physical and socioeconomic environment. This paper summarizes the rationale for this special issue, identifies the key issues addressed in the contributions and provides a concise research framework for further work on Africa. One of the primary goals of this framework is to develop regional integrated assessment models for Africa. These models are a necessary step towards strengthening the analysis of impacts and help make the necessary connection between science understanding, resource management and public policy. Integrated assessments will also help incorporate climate change analysis and prediction in sustainable development schemes.
\end{abstract}

KEY WORDS: Africa climate change research $\cdot$ Climate variability $\cdot$ Desertification $\cdot$ Land-use change $\cdot$ Regional assessment models

Resale or republication not permitted without written consent of the publisher

\section{INTRODUCTION}

Unlike many other special issues, this one did not arise from a particular research project, rather, it emerged out of the excitement over the International Panel on Climate Change (IPCC) Third Assessment of

*E-mail: desanker@virginia.edu
Impacts and Adaptation to Climate Change and the need to highlight some of the emerging science results from African work on climate change. The Editors of Climate Research were particularly interested and encouraging, and this is the result. In this introductory paper, we highlight the main results from the contributions, expand on some emerging themes and develop a concise agenda for the future. 
It has long been recognized that, given Africa's size, diversity in climate and language, and critical issues facing it, it is a major challenge to construct a well-balanced overview of issues of climate change, or for that matter, any other environmental issue that relies, in part, on social, political and physical characteristics at the sub-regional level. It has also been recognized that, relative to other parts of the World, climate change in Africa has received relatively little attention but could have some of the greatest impacts. To give more visibility to African global change issues, an open call for papers was released, inviting contributions, especially in those regions of Africa that are not well represented in the English literature, to address pertinent research issues including the following:

- Past and future climate scenarios, descriptive statistics, extreme events

- Regional climate modeling results

- Vegetation changes over palaeo time-scales

- Climatic variability and degradation

- Degradation and desertification

- Population, the environment and global change

- Adaptation to droughts

- Feedbacks and interactions: biophysical, socioeconomic, policy

- Land use and global change

- Hydrological impacts of global change-major catchments, watershed level, including related impacts of land-use change

- Impacts on agriculture: food security implications

- Climate change and human health

- Sustainability, development and global change

- Policy implications: development paradigms, policy opportunities

This list attempted to cover topics that would help enhance our understanding of climate change issues. The papers that came in addressed several of these topics, underscoring the wealth of information on Africa's physical climate and showing that little attention is currently being given to research on impacts and adaptation, despite several international efforts to facilitate such research.

\section{AFRICA'S CLIMATE}

The first 4 papers in this special issue (Olago 2001, Nicholson 2001, Hulme et al. 2001, Semazzi \& Song 2001) discuss climate from palaeo time-scales to the present and provide some indications of how climate might change over the next century. This group of papers summarizes many years of research on African climate and offers many useful suggestions for strengthening this area of research in the coming decades to improve our understanding of climate change in Africa.
Olago (2001) synthesizes vegetation changes as indicated by palaeo studies going back 30000 yr BP. His review indicates that temperatures during the last glacial maximum (22000 to 14000 yr BP) were between 4 and $7^{\circ} \mathrm{C}$ lower than today, while the current climate was reached roughly 3000 yr BP.

Nicholson (2001) offers a comprehensive summary of rainfall patterns across Africa based on extensive analysis of the in situ instrument record for the 20th century and discusses the processes producing the long-term trends. These processes include meteorological factors as well as land-surface effects such as land-use change, desertification, the albedo question and dust. Nicholson concludes that the most significant climatic change that has occurred in Africa is a longterm reduction in rainfall in the semi-arid regions of West Africa. She shows that while most of the Africa region has been affected by increased aridity, particularly since the 1980s, the change has been greatest over parts of the Sahel (20 to $40 \%$ between the periods 1931-60 and 1968-1997). Nicholson highlights the potential for large-scale anthropogenic modification of the land surface to influence regional climates and recommends support for improved large-area monitoring and estimates of the degree of change to improve this kind of analysis and modeling.

Hulme et al. (2001) describe a gridded climate database they have constructed over the last decade for the last $100 \mathrm{yr}$ and discuss possible future climate for the next hundred. The future scenarios draw upon the latest emissions scenarios of the IPCC's Third Assessment Report (TAR) and use a simple climate model to link the emissions scenarios with recent global climate model (GCM) experiments. They discuss the major limitations in knowledge of future African climates from models including poor representation of $\mathrm{El}$ Niño/Southern Oscillation (ENSO) climate variability in GCMs and the absence in these models of any representation of regional changes in land cover, dust and biomass aerosol loadings. The 4 climate futures presented should serve as useful inputs into national and regional vulnerability and adaptation assessments. Methods described by Hulme et al. are applied widely in the IPCC TAR and represent an approach that could be used in impact assessments in Africa. The input data are available through the IPCC Data Distribution Center (www.ipcc.ch); the simple climate model used is also available and widely utilized.

Semazzi \& Song (2001) use a GCM over Africa and explore the implications of deforesting the tropical rain forest regions of Africa and replacing them with savanna grassland vegetation. While this is an extreme form of land-use conversion, it demonstrates very effectively that land-use changes can have impacts on climate and that some of these impacts are felt far from 
the region that is deforested, through a process called teleconnection. These results highlight the need for accurate representations of the land surface in climate modeling studies and underscore the work needed to document land-cover change and provide spatially explicit data sets to drive regional climate modeling projections.

\section{ECOSYSTEM STUDIES, MONITORING AND IMPACTS}

Cao et al. (2001) apply a biogeochemical model to simulate carbon dynamics between 1901 and 1995 in response to climate change and $\mathrm{CO}_{2}$ changes. They conclude that climate change reduces plant production and soil carbon stocks and causes net $\mathrm{CO}_{2}$ release, but the fertilization effect of increasing atmospheric $\mathrm{CO}_{2}$ on photosynthesis reverses the reduction and leads to carbon accumulation in vegetation. The mean rate of the carbon sequestration in the period 1981-95 is cal-

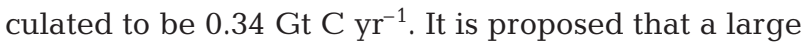
part of the carbon sequestration is offset by the carbon release arising from land-use change and hence, highlights the need for monitoring of land-cover changes to improve treatment of carbon balance in relation to land use.

In the next paper, Dube \& Pickup (2001) apply Landsat satellite data to demonstrate methods for monitoring impacts of climate variability and human activity (grazing) on vegetation. Their methods apply to semiarid regions and offer useful examples of the types of methods that must be used to accumulate information about change. They discuss complications in disaggregating causes of the vegetation change that are observed. Landsat data are widely available for most parts of Africa and are a source for the land-use information needs highlighted in the other papers.

Feddema \& Freire (2001) apply a water balance model to evaluate the combined effects of soil degradation and global warming at the major basin level. They found that in general, reduced water holding capacities will result in increased water runoff during wet periods, which will result in higher overland flow rates and reduced recharge rates to groundwater. Water lost to runoff will also increase deficits during dry periods, in effect increasing the duration and intensity of dry periods. The framework that they have designed would be a useful prototype for further analysis using the new IPCC scenarios and improved datasets of the land surface as these become available for Africa.

Gonzalez (2001) reports on a unique field-based study that analyzed tree species richness and density in the West African Sahel over a period of $50 \mathrm{yr}$ and demonstrates reductions in both. The rigorous methods used are a good example of ground-based measurements needed in many parts of Africa to document change, especially in areas that are undergoing major environmental change. Gonzalez shows that ecological and socioeconomic factors favor the natural regeneration of local species over the massive plantation of exotic species. The documented reductions in tree species and tree density offer evidence for persistent land degradation and desertification.

Justice et al. (2001) report on work that is ongoing in the Central African tropical forests. They provide an assessment of the current state of the forests of Central Africa, their carbon stock, recent rates of deforestation and a simple predictive model of forest change over the next 60 yr. Suggestions are made for potential carbon trading projects, forest management strategies and a climate change research agenda for the region. They also highlight the importance of monitoring, for example, using remote sensing at the regional level. Their efforts at quantifying a baseline land cover for the Central Africa rain forest region should greatly improve the inputs into future climate modeling studies for this region. This mapping should greatly enhance regional climate modeling efforts that manipulate the rainforest to examine impacts on climate.

\section{KEY RESEARCH ISSUES FOR AFRICA}

There are a number of research issues that emerge from the above papers and recent results on African global change that are worthy of additional consideration.

\subsection{Trends in African climate: precipitation and temperature}

Most environmental concerns in Africa are linked to water and rainfall. Rainfall has attracted the most attention and good databases exist, although some areas such as the Congo Basin have extremely patchy and limited coverage. The patterns of rainfall variability and controlling processes are generally well understood, with warmer conditions in the Atlantic and Indian Oceans tending to promote drier conditions over the continent as a whole (Nicholson 2000a, 2001). Long-term reduction in rainfall in the semi-arid regions of West Africa has been clearly demonstrated by Nicholson's work and by others. The increased availability of climate records in public databases has greatly enhanced analysis of African rainfall, and efforts to improve data availability should be continued. However in some countries more recent data are 
less available, as financial support for weather observation networks is dwindling. In general the in situ observations are in decline at a time when reliable hydrological monitoring networks need updating with new equipment and digital media.

The needs of the impacted community are usually quite simple and expressed in very succinct waysthey need to know whether it's getting drier or wetter, and when and where.

There has been little interest in analyzing temperature patterns in Africa, given the overriding critical role of water. However, there is increasing evidence of temperature controls of important physiological processes in insects, plants and crops. Diurnal range in temperature, frost conditions, and lowest temperatures are important in controlling flowering and fruiting, as well as life cycles of some insects. At the global scale, thresholds in temperature that would cause ecosystem damage are being sought, and these are likely to be early signs of adverse impacts of climate change on terrestrial ecosystems. These temperature impacts are likely to be equally important in freshwater ecosystems, where water temperatures are important in controlling chemical processes, as well as physiological functioning of fish and other marine life. The understanding of basic physiological functioning is a clear starting point before negative impacts can be identified. This calls for expanded basic research on component ecosystems in Africa, a far cry from the current suite of applied environmental issues. Analysis of temperature elsewhere has shown significant changes in minimum temperatures (e.g. DeGaeteno 1995, Karl 1996, and Easterling et al. 1999 for the United States; Plummer 1999 for New Zealand; and Heino et al. 1999 for Northern and Central Europe). Analysis of trends in temperature as well as precipitation based on available data is a priority.

For regional and national level applications, it is desirable to have finer resolution climate surfaces or gridded data sets than the prevailing half-degree gridded variables from the International Institute of Applied Systems Analysis (IIASA, Cramer \& Leemans 1992) or the Climate Research Unit database (New et al. 2000). While a few countries, such as South Africa, may have improved climate surfaces, the majority of Africa does not, making impact assessments at fine resolutions impossible.

\subsection{Climate variability, extreme events and CLIVAR}

Large areas of Africa already experience considerable year-to-year variability in rainfall, and land-use systems have evolved to accommodate this variability. There is fairly good understanding of the patterns of rainfall variability for Africa (see Nicholson 2001 and many of her papers and references therein). Changes in climate variability are difficult to characterize at any given location or sub-region, as data are often limited. However, climate change is likely to manifest itself through a change in variability as well as in magnitude (amount of rainfall or average temperature).

Many studies agree that extreme climate events will increase or get more intense in the future under a changing climate (IPCC TAR, IPCC 2001). For many parts of Africa, countries face either drought or floods, and sometimes both in different parts of the country in any given year, for example, Mozambique during early 2001. Floods result in very high costs in infrastructure (roads, rail, bridges) and, depending on severity, can result in high losses of human life. Livestock and a whole year's crop are easily lost, bringing extreme hardship to mostly rural and subsistence farmers, who are often already struggling to maintain their livelihood. Droughts and resultant water and food scarcity are less abrupt in their realization, but can lead to just as much suffering and loss of life, especially for children and the elderly. There is increasing awareness of when and where these extreme events occur, as well as studies linking them to large-scale processes such as ENSO and ocean temperatures. Early warning will reduce adverse impacts, while longer-term preventative planning will ensure that infrastructural damages are minimized, and emergency response measures put in place. The integration of social-economic and political factors into any adaptation efforts is now widely accepted as critical.

Continued maintenance of weather stations with standardized measurements, especially those with very long records, is critical to understanding patterns of variability at key locations and how they may change over time. Statistical methods exist for analyzing spatial variability, given daily records, and these methods should be used at the scales at which landmanagement decisions are made.

The Africa Climate Program of CLIVAR (Climate Variability and Predictability Project of the World Climate Research Programme-WCRP) has developed an implementation plan that is expected to improve our understanding of the nature of climate variability in Africa and will hopefully lead to improved climate models and regional climate predictions in Africa. The 3 main questions that CLIVAR-Africa (WCRP 2000, see also http://www.clivar.org) is addressing are:

- What are the causes of African climate variability and how is it related to other parts of the globe?

- How well do current dynamical models simulate African climate variability and its relationship with global climate? 
- Which deficiencies do dynamical models have that can account for known inadequacies in the simulation of African climate variability and its relationship with the global climate?

The CLIVAR activities are expected to produce results that will greatly enhance our understanding of how climate is changing and some explanation of the climatic processes leading to recent damaging extreme events, such as the Mozambique floods of 1999/2000. Improved understanding of the ENSO will improve climate forecasting and, in turn, increase success of adaptation measures.

\subsection{Possible spatial and temporal shifts in climate}

Human communities have developed livelihoods and traditional land uses suited to prevailing climatic conditions of their local environment. Types of cropping and farming regimes have evolved to take advantage of seasonal patterns (whether uni- or bi-modal) and amount of rainfall. Planting calendars and related preparatory work have all evolved with a long-term understanding of climatic conditions, although seasonal forecasts of rainfall are increasingly being used to fine-tune planting dates. Global climate change is likely to result in major shifts in climatic conditions at any given sub-region as shown by regional modeling studies such as Semazzi \& Song (2001), both in space and over the year. This is likely to disrupt growing conditions and result in crop failures, and would have serious implications for food security. People in several parts of Africa are currently experiencing such crop failures due to erratic and shifting patterns in rainfall, but these cases are not always documented. Systematic documentation and publication of these cases is required to build up a knowledge base of how much damage is occurring and where. Current national annual statistical summaries need to incorporate details that will contribute to this monitoring of climate change and its impacts, information that will be very useful in national communications to the Framework Convention on Climate Change. Knowing when conditions have changed sufficiently enough to warrant a change in land use, such as which crops to grow, is perhaps one of the bigger challenges facing communities.

\subsection{Land-surface feedbacks and desertification}

There is growing recognition of the nature of feedbacks between the land surface (land cover, surface albedo and soil moisture) and the atmosphere, and how these land-surface properties themselves are impacted by climate variability, land use and land degradation (Hunt 2000, Nicholson 2000b). Studies show that global ecosystems are stabilized by a series of feedbacks between man, animals, soils, vegetation and climate (Schlesinger et al. 1990, Graetz 1991); in undisturbed arid environments in equilibrium the feedback loops tend to be negative, hence preserving the status quo, while the disturbances induced by desertification make some of the feedback loops positive, allowing the disturbance to be amplified. Thus the potential exists for desertification to become self-accelerating, with droughts promoting the process (Nicholson 2000b). There is a need to understand these linkages and feedbacks, with monitoring providing data to validate model results. There is a need for more accurate, longer and more extensive data sets of the land surface in relation to observed climatic processes at the regional level to enable improved assessments of possible desertification (as driven by land degradation and human land-use change) and regional rainfall changes. Integrated experiments such as Hapex-Sahel (Goutourbe et al. 1997) are very useful, although less intensive and longer-running observations over more sensitive regions are needed to complement such intensive campaigns. There is an emerging international effort under the Global Terrestrial Observing System (GTOS) to strengthen the observing networks. Coordination between the land-cover change observation networks (such as the new Global Observation of Forest Cover [GOFC] program-http://www.gofc.org) and the climate observation systems is needed to allow integrated analyses.

\subsection{Land-use-land-cover change}

The study of land use is fundamental in attempts to link production systems with climatic, social and economic processes and to determine how these contribute to sustainable development. A few case studies at the local level exist in African systems, but there is a general lack of synthesis of land use going from the local/community levels to the regional level. The landuse modeling components of global integrated assessment models (IAMs) such as IMAGE 2 (Alcamo 1999) do not contain the level of detail required for nationallevel land-use planning (Desanker et al. 2001). In principle, it is now possible to develop detailed land-use change models for most African countries by using remote sensing data (such as those from Landsat 5 and 7 ) and socio-economic data that is available at district levels for many countries. The recent decommercialisation and open data policy of Landsat 7 has opened up access to regional scientists and made data available at affordable prices. The global acquisition strategy of 
Landsat 7 collects data over parts of Africa where in the past data collection has been sparse due to the absence of ground receiving stations. Verification and validation of derived products from these remotely sensed observations is critical in getting the community (global and regional to local) to understand the potential and limitations of these new data sets for the African environment and to recognize these new types of evidence of change.

Studies of land use also enable the human dimensions of climate change to be properly placed in the context of livelihoods and social development (Vogel et al. 2001). Understanding people's perceptions and responses to climate and extreme events such as droughts enriches our ability to assess impacts of climate and how adaptive capacity can be enhanced.

\subsection{Africa futures: scenario development and location-based studies}

The IPCC have released their latest global emissions and social-economic scenarios (SRES Special Report, IPCC 2000) to replace the much used emissions scenarios of 1992 (IS92). The SRES provide a series of plausible emissions scenarios based on assumptions about the future evolution of major drivers of emissions, namely technology, economics, energy and population. While these drivers are given at the Africa level of aggregation (or sub-Saharan Africa in some cases), they provide a methodology and upper bounds for Africa that would be useful to extend to provide more detailed projections at the country level or better. There are studies from the social and political sciences for Africa that explore future scenarios, e.g. 'Alternative Futures for Africa' (Shaw 1982) and 'Farewell to Farms' (Bryceson \& Jamal (1997). It will be important to engage this research community in developing social-economic scenarios for Africa that reflect what is known more clearly than global assessments are able to. The issues of development are likely to have overriding influence on any future scenarios for Africa, making it critical that a solid understanding of development be included in the further development of scenarios. In order to capture the climate issues relevant for livelihoods, locationbased assessments are needed to complement the broad impact assessments such as those described in country studies guides (Feenstra et al. 1997).

The emission scenarios are used to drive climate change forcing in GCMs. Where regional climate models exist, better resolution is possible for applications in regional and local studies of climate change. There is a need to explore the utility of these regional climate modeling approaches in enriching the development of climate change scenarios for Africa.

\subsection{Data issues, monitoring and documenting evidence of climate change}

Those working in Africa often bemoan the lack of data for research, and this depends a great deal on African access to the latest information technologies. There is a wealth of information on Africa from satellites, global studies, and various national sources, and increasingly this information is being deposited on Web sites across the world. However, for other than a few countries, Africa remains largely unconnected to the Internet. For those in Africa, this is a major constraint to doing research and understanding the state of knowledge. A short-term solution is to have African scientists spend time with colleagues in countries with ready access to the Internet to conduct some of their background work; however, it is not clear how long it will take for access to improve in Africa to a point where it is truly useful.

A useful collaboration between international initiatives and local ones is needed to capitalize on many land-cover monitoring activities now underway. The recent development of the Miombo Network for Southern Africa (Desanker et al. 1997) and the OSFAC science network for Central Africa (Mayaux et al. 2000) provides good examples of this collaboration. GOFC has recognized the importance of strong regional science networks to help implement operational longterm monitoring programs (Ahern et al. 2000). The data collected by these monitoring systems also need to be archived locally to make them more accessible to African scientists.

For climate data, precipitation and temperature data are usually archived in openly accessible data centers such as the NOAA NCDC (http://www.ncdc.noaa.gov). However, the density of stations is still very low for Africa, and in any case, they do not fully represent the climate data that is collected and archived in national meteorological offices. There is an ever-increasing need for access, in a timely fashion, to the national data in order to evaluate major events, such as droughts and floods, as they occur.

Weather-map satellites are a useful source of data for analyzing observed climate at the regional scale (e.g. Jury \& Majodina 1997). Although many African countries are able to receive weather-satellite information, many do not have archiving facilities.

For sites where long-term climate data exist, there is a need to evaluate any significant changes in climate. This should extend to analyses of human and ecological systems and how they have been impacted by climate. The latest IPCC report (TAR) will emphasize documentation of evidence of climate change and impacts-for Africa, there are very few studies to go by, despite the many obvious impacts of climate. 
Past extreme events, especially droughts, floods and storms, provide useful analogs of what future adverse impacts might involve. The progression of these events, and their economic and social impact, levels of damage, human response and recovery, offer useful guidance in devising future adaptation measures. It is recommended that all major events be properly documented and published with retrospective analysis on cause and effect. While experiments in adaptation are harder to do, it would be useful to test methods for adaptation that would assist the climate change convention in their implementation efforts.

\subsection{Assessment process in relation to the IPCC}

The IPCC process synthesizes the best available published knowledge, and their reports are indeed the best reviews and syntheses of the topics covered. For Africa, much information is unpublished and largely unavailable to the international community. Documentation of impacts, responses and other studies specific to climate are few. For Africa to be adequately addressed in the IPCC process, it is essential that a deliberate documentation of climate phenomena and impacts at the local level be carried out, and the results made more widely available. This will take increased international coordination and mobilization of new resources. It will be necessary to be very specific about significant impacts for different regions in future, rather than rely on the usual hand-waving about Africa being very vulnerable because it is poor, and so on. Sub-regional specificity is required. There is a need to study the latest IPCC reports for major findings and to enrich those conclusions dealing with Africa with more examples and local context. It would be very valuable to translate the IPCC TAR findings into statements that policy makers and resource managers can use in Africa.

\subsection{Scientific capacity building and climate change}

An important issue for African science is the need for increased capacity to undertake climate change research. There are a considerable number of African scientists with keen insight into the processes that shape their environment, but few of these are supported in addressing questions of global change. The university structure in most African countries is well established, but there is an urgent need to build strong programs in environmental science, particularly at the doctoral level, that will produce interdisciplinary scientists capable of tackling the global change research agenda. The shortage of resources for basic research points to the need for strong and ongoing collaborations between African and non-African universities.

There will always be capacity building needs in Africa. Strategies are needed that address the pipeline of training from technical to management and policy, addressing the broad suite of issues related to climate change, in relation to the other factors that African leaders view as important-agriculture, health, poverty and water.

\section{INTEGRATED ASSESSMENT AND MODELING FOR AFRICA}

Quantifying sensitivity to climate change, societal resilience, adaptive capacity and the costs of impacts are major gaps in our current assessment of climate change in Africa if not globally. Research is needed to test approaches and indicators for Africa, building upon available data and, at the same time, identifying gaps and suggesting new data that need to be collected. It is possible that development of integrated assessment models (IAMs) will address elements of this issue. IAMs are becoming tools of choice for assessing impacts and adaptation options for climate change. When policy responses are implemented in IAMs linked to biophysical, climatic, social and economic processes, consistent evaluation of adaptation and vulnerability becomes possible. Many of the extant IAMs are global and necessarily aggregate regions based on economic activity; thus, Africa is always aggregated into 1 region. While the outputs from these global IAMs are suitable for global assessments, they offer little guidance to the sub-regions of Africa, where differences range from desert to rainforest and where, in many cases, there is very limited connectivity (physical, trade or otherwise) between subregions. It is therefore critical that regional IAMs be developed for parts of Africa, with incorporation of regionally relevant issues of sustainable development clearly highlighted. Where feasible, it would be useful to have such IAMs for each nation, constructed in such a way that sustainable development planning could be incorporated easily.

Guided by the papers in this special issue and discussions during the IPCC assessment process, we have identified a set of activities that would lay the backbone of integrated assessment and modeling for Africa, at the continental level, for subregions (including river basins), and at the national level. These desired activities are entirely achievable given the present status of data and would greatly enhance future assessments and any plans to identify projects that would help in adapting to adverse impacts of climate change. 


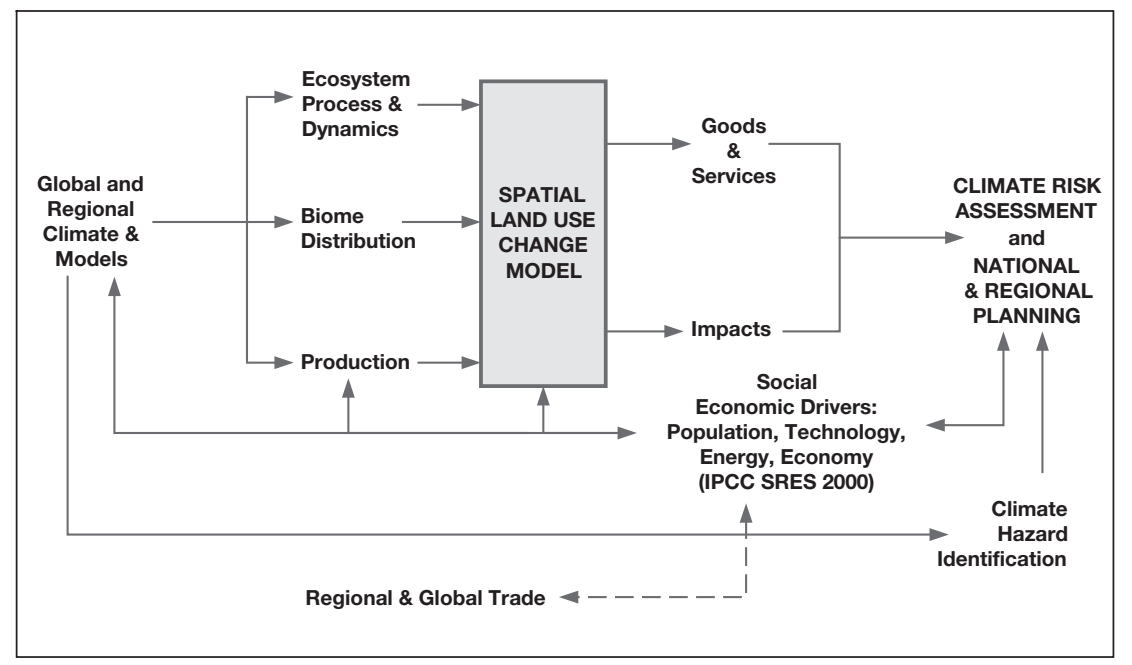

Fig. 1. Flow of activities and modeling proposed to support integrated assessments in Africa. Analysis of climate data as well as regional and global climate models would provide the necessary constraints for ecosystems, vegetation distribution and production, which in turn would be used in the land-use model to explore ecosystem goods and services and impacts, the foundations of development planning and natural resources management. Identification of climate hazards would be translated into assessments of risks, given population distributions and adaptive capacity within national plans. Such a flow of activities is possible given the spatial and socio-economic data now available for Africa and at high resolution for many countries. Some of the biophysical modeling would be carried out at a continental level, while some of the impacts would be at the river-basin, national or local levels, depending on context

The proposed activities (Fig. 1) are centered on developing a comprehensive land-use-change model that would couple ecosystems, production and national development plans, given the physical, economic and climatic factors of a country, as the basis for planning and response actions. Existing global IAMs do not have the resolution over Africa to capture the important processes and constraints to land use and development. In fact, they lump Africa (or sub-Saharan Africa in some cases) as 1 geographic region-despite the large number of countries involved and obvious social, economic and political constraints that this imposes. Many important decisions and policies are set at the national level, and so we view national resolution as a critical element of our proposed integrated modeling approach.

Some of the modeling activities can be carried out at the regional or continental level without loss of generality. Some place-specific studies are needed, and the emphasis would shift accordingly. Below, we give a breakdown of studies and subregions at which the integrated assessments should be carried out:

\subsection{Africa-wide modeling}

Many biophysical aspects of climate change can easily be addressed for the continent as a whole, with links to the global systems as needed. These include analysis of large-scale climate variability and scenarios, spatial and temporal shifts in climate and associated shifts in vegetation biomes, large river hydrology, crop and tree distributions. The tool kits for this in terms of computer models and approaches are well developed. Data are largely available, but could be improved with local sources. This level would also develop scenarios for the whole continent for regional application. These should build on the latest IPCC scenarios (SRES, IPCC 2000) and be enriched by studies on African futures scenarios.

\subsection{Regional integrated studies designed to overlap with existing economic and policy partnerships}

Sahel region: Climate variability and agriculture, water, natural resources management, desertification, land-surface-atmosphere feedbacks and droughts, ENSO, resource-use conflicts, livelihoods.

East and Horn of Africa: Droughts and floods, disease vectors, intra-annual climate variability and agriculture (impacts of rain failures and shifts in seasonal rainfall patterns), conservation and indigenous people issues, livelihoods.

Southern Africa: Drought and floods, climate variability and agriculture, water quality, land use, livelihoods, shared resources, hazards from dam control in shared river basins. 
Central Africa: Land use/deforestation and carbon, biodiversity, intra-annual climate variability impacts on agriculture.

Magreb region: Droughts and water, irrigation, desertification, livelihoods and fisheries along the coast.

Coastal zones: Flooding, fisheries, pollution, impacts of land-use and water management within the river basin, coral reefs, settlements and infrastructure. Coastal and flood plains are more densely populated than inland areas, placing large proportions of the population at risk to climate extremes.

River basin integrated studies: Major river basins are useful integrating frameworks of land use, politics, etc., because of the interdependence on common water and shared burden of adverse impacts of land use across the whole basin. Many studies exist at this scale, and there is potential for enriching these with climate change assessments. There is a need for integration of land-surface-atmosphere feedbacks over the basins and coupling of this to land-use and ecosystem processes to provide a fully dynamic assessment. This would greatly enrich the many studies that have been carried out, most of which provide relatively static states of the environment.

\subsection{National and local integrated assessments}

Case studies of national-regional integration: The interactions through trade and shared resources of a country with its regional partners and the global system, and constraints on national development. This would include issues of globalization versus selfreliance. This is a scale at which important policies are made in relation to (sustainable) development goals, and has been largely ignored in past IAMs given the large number of countries in Africa.

Local studies: Studies are needed at the local community level to capture the social dimensions of climate change and how social agency and human decisions work. This should include rural, urban and indigenous groups, spanning a cross-section of adverse climate hazards -including drought, floods, and climate variability.

\subsection{Cross-cutting themes}

Desertification and climate change: The linkage between issues of land degradation and desertification with climate are critical in arid and semi-arid areas of Africa. It is necessary to separate the science from rhetoric, but at the same time, there is a need to link the science with the human dimensions a lot more explicitly. There is great need in Africa to make these
2 communities come together before progress in integrated assessment is made.

ENSO: A great deal of work is being done on the ENSO, including seasonal forecasting in relation to agricultural activities, health and extreme events (drought, storms and floods). Some links to this work are needed to provide scenarios and results that are reliable to the impacts community. The CLIVAR program for Africa has a comprehensive schedule that should contribute in significant ways.

Multiple stresses, feedbacks and thresholds: It is well accepted that climate operates in a mix of multiple stresses and factors, many of which are not related to climate or climate change. It is important to evaluate climate change in the context of these factors, especially when addressing sustainable development and funding issues. Thresholds for system/ecosystem failure are an important area of research. The nationallevel integrated assessments should include analysis of multiple stresses as well as some of the regional integrated modeling.

Livelihoods, development and climate change: The role of climate and geography in livelihoods, development and the inter-linkages with climate change impacts, vulnerability and adaptation is important to explore. This will provide insights into how adaptation can be incorporated into sustainable development plans. This is a critical area of research that will determine success of implementation of adaptation.

Identification of climate hazards to guide adaptation activities: There is growing concern about the impacts of climate extreme events (floods, cyclones, droughts, etc.), especially among the least developed countries, given their very limited capacity to adapt and recover from such disasters. Careful analysis of the current situation in light of how climate variability and extremes might change is necessary before informed adaptation activities can be undertaken. The framework described in Fig. 1 can be used to assess climate-related hazards by examining flood and drought risk in the spatially explicit setting of the land-use model. Maps can be developed showing areas at risk, and these can be overlaid with population and other baseline information such as infrastructure to assess risk and to design adaptive measures. This is an area that is likely to be of wide interest in the coming years as countries design adaptation programs.

\section{CONCLUSION}

Climate change is one of several major environmental issues that African countries must participate in. The others, including combating desertification, conserving biodiversity, and sustainable development, 
demand equal and oft-times more attention. Research in Africa could be designed to address many of these issues concurrently, and the suggested integrated modeling would assist in providing the necessary linkages to policy and other societal needs. It is clear from the papers in this special issue that considerable progress has been made in understanding African climate. Africa's diversity of climates, ecosystems, politics and social systems demand that impact studies consider these factors explicitly. Extreme climate events are likely to be a major area of concern over the coming decades - this requires more monitoring and analysis of observations and development of new techniques for identifying potential climate hazards in very specific geographic terms. It is our hope that the papers in this special issue provide a useful insight into some of the research that is going on and the data that is available and will spark interest for the coming years to address the many critical issues that have been flagged.

Acknowledgements. It is gratifying to see this special issue come to fruition, especially as it was not the result of a specific project. The willingness of the authors to write these papers and to wait for some of the papers that took longer to process is commendable. This was a challenging but extremely rewarding initiative and is a tribute to the African scientists working on global change research, often in difficult situations. Through this CR SPECIAL, we were able to work with some of the leading experts on Africa's climate and environment. These papers provide examples of the substantive global change research that is being undertaken and move the subject beyond the usual sweeping statements about climate variability, extreme events and Africa's high vulnerability. It is hoped that this special issue will result in new interest in this aspect of African research. We are grateful to the reviewers that assisted in improving the papers, in some cases significantly, as well as feedback from the lead authors of Chapter 10 (the Africa chapter) in the IPCC Third Assessment Report, Working Group II. P.V.D.'s time on this project was made possible by support from NASA Grant NAG5-6384.

\section{LITERATURE CITED}

Ahern F, Gregoire JM, Justice C (eds) (2000) Forest fire monitoring and mapping: a component of global observation of forest cover. Report of a Workshop, November 3-5, 1999. European Commission Joint Research Centre, Ispra

Alcamo J (ed) (1994) Image 2.0 integrated modelling system for global climate change. Kluwer Academic Publishers, Dordrecht

Bryceson DF, Jamal V (eds) (1997) Farewell to farms, deagrarianisation and employment in Africa. Ashgate Publishing Ltd, Aldershot

Cao M, Zhang Q, Shugart HH (2001) Dynamic responses of African ecosystem carbon cycling to climate change. In: Desanker P (ed) Africa and global climate change. CR SPECIAL 8. Clim Res 17:183-193

Cramer WP, Leemans R (1992) The IIASA database for mean monthly values of temperature, precipitation, and cloudiness on a global terrestrial grid. International Institute for
Applied Systems Analysis (IIASA) Research Report91-018, Laxenburg

DeGaetano A (1996) Recent trends in maximum and minimum temperature threshold exceedences in the Northeastern United States. J Clim 9:1646-1657

Desanker PV, Frost PGH, Justice CO, Scholes RJ (1997) The Miombo Network: framework for a terrestrial transect study of land-use and land-cover change in the Miombo ecosystems of Central Africa. IGBP Report No. 41, International Geosphere-Biosphere Programme, Stockholm; also available at http://miombo.gecp.virginia.edu

Desanker PV, Justice CO, Masamvu K, Munthali G (2001) Requirements for integrated assessment modelling at the subregional and national levels in Africa to address climate change. In: Lo PS (ed) Climate change for Africa: science, technology, policy and capacity building. Kluwer Academic Publishers, Dordrecht

Dube OP, Pickup G (2001) Effects of rainfall variability and communal and semi-commercial grazing on land cover in southern African rangelands. In: Desanker P (ed) Africa and global climate change. CR SPECIAL 8. Clim Res 17:195-208

Easterling DR, Diaz HF, Douglas AV, Hogg WD, Kunkel KE, Rogers JC, Wilkinson JF (1999) Long-term observations for monitoring extremes in the Americas. Clim Change 42: 285-308

Feddema JJ, Freire S (2001) Soil degradation, global warming and climate impacts. In: Desanker P (ed) Africa and global climate change. CR SPECIAL 8. Clim Res 17:209-216

Feenstra JF, Burton I, Smith JB, Tol RSJ (eds) (1998) Handbook on methods for climate change impact assessment and adaptation strategies, Vol 2.0. United Nations Environment Program, Nairobi, and Institute of Environmental Studies, Vrije Universiteit, Amsterdam. Available at: www. vu.nl/english/o_o/instituten/IVM/research/climatechange/ Handbook.htm

Gonzalez P (2001) Desertication and a shift of forest species in the West African Sahel. In: Desanker P (ed) Africa and global climate change. CR SPECIAL 8. Clim Res 17: 217-228

Goutorbe JP, Kabat P, Kerr YH, Monteny B, Prince D, Stricker JNM, Tinga A, Wallace JS, Lebel T, Dolman AJ, Gash JHC (1997) An overview of HAPEX-Sahel: a study in climate and desertification. J Hydrol 188-189:4-17

Graetz RD (1991) Desertification: a tale of two feedbacks. In: Mooney HA et al. (eds) Ecosystem experiments. John Wiley and Sons, Chichester, p 59-87

Heino R and 10 others (1999) Progress in the study of climate extremes in Northern and Central Europe. Clim Change 42:151-181

Hulme M, Doherty R, Ngara T, New M, Lister D (2001) African climate change: 1900-2100. In: Desanker P (ed) Africa and global climate change. CR SPECIAL 8. Clim Res 17:145-168

Hunt BG (2000) Natural climatic variability and Sahelian rainfall trends. Global Planet Change 24:107-131

IPCC (2000) Emissions scenarios, 2000. Special Report of the Intergovernmental Panel on Climate Change. Nakicenovic N, Swart R (eds) Cambridge University Press, Cambridge

IPCC (2001) Summary for policy makers, climate change 2001: impacts, adaptation, and vulnerability. Report of Working Group II of the Intergovernmental Panel on Climate Change, Geneva

Jury MR, Majodina M (1997) Preliminary climatology of southern Africa extreme weather: 1973-1992. Theor Appl Climatol 56:103-112 
Justice C, Wilkie D, Zhang Q, Brunner J, Donoghue C (2001) Central African forests, carbon and climate change. In: Desanker P (ed) Africa and global climate change. CR SPECIAL 8. Clim Res 17:229-246

Karl T, Knight RW, Easterling DR, Quayle RG (1996) Indices of climate change for the United States. Bull Am Meteorol Soc 77:279-291

Mayaux P, Justice C, Lumbuenamo RS (2000) Atelier de création du réseau GOFC-OSFAC en Afrique Centrale, Libreville, Gabon, February 22-24, 2000, GOFC, Ontario. Available at: www.gofc.org/gofc/docs/osfac.pdf

New MG, Hulme M, Jones PD (2000) Representing twentiethcentury space-time climate variability. Part II: Development of 1901-1996 monthly grids of terrestrial surface climate. J Clim 13:2217-2238

Nicholson SE (2000a) The nature of rainfall variability over Africa on time scales of decades to millennia. Global Planet Change 26:127-158

Nicholson SE (2000b) Land surface processes and Sahel climate. Rev Geophys 38:117-139

Nicholson SE (2001) Climatic and environmental change in Africa during the last two centuries. In: Desanker P (ed) Africa and global climate change. CR SPECIAL 8. Clim Res 17:123-144

Submitted: January 14, 2001; Accepted: May 15, 2001
Olago DO (2001) Vegetation changes over palaeo-time scales in Africa. In: Desanker P (ed) Africa and global climate change. CR SPECIAL 8. Clim Res 17:105-121

Plummer N (1999) Changes in climate extremes over the Australian region and New Zealand during the twentieth century. Clim Change 42:183-202

Schlesinger WH, Reynolds JF, Cunningham GL, Huenneke LF, Jerrell WM, Virginia RA, Whitford WG (1990) Biological feedbacks in global desertification. Science 247: 1043-1048

Semazzi FHM, Song Y (2001) A GCM study of climate change induced by deforestation in Africa. In: Desanker P (ed) Africa and global climate change. CR SPECIAL 8. Clim Res 17:169-182

Shaw TM (ed) (1982) Alternative futures for Africa. Westview Press, Boulder, CO

Vogel C, Chanda R, Arntzen J, Ringrose S, Hoffman T, Desanker P (2001) The human dimensions of environmental change in southern Africa: a preliminary synthesis. $\mathrm{S}$ Afr J Sci (in press)

WCRP (2000) CLIVAR Africa implementation plan, World Climate Research Programme (WCRP) Information Report No. 5. International CLIVAR Project Office, Southampton

Proofs received from author(s): July 2, 2001 